\title{
Research on Impact Performance of Hydraulic Rock Drill with Floating Characteristics of Double Damping System
}

\author{
Yelin Li (D, Zeng Bin, and Yi Tu \\ Hunan Province Cooperative Innovation Center for the Construction \& Development of Dongting Lake Ecological Economic \\ Zone, Hunan University of Arts and Science, Changde 415000, China
}

Correspondence should be addressed to Yelin Li; liyelin0403@aliyun.com

Received 4 August 2019; Revised 8 October 2019; Accepted 15 October 2019; Published 7 November 2019

Academic Editor: Davood Younesian

Copyright $(92019$ Yelin Li et al. This is an open access article distributed under the Creative Commons Attribution License, which permits unrestricted use, distribution, and reproduction in any medium, provided the original work is properly cited.

As a technological innovation of high-power hydraulic rock drill, double damping system has a very important effect on impact performance. The double damping system is a floating mechanism. The characteristics of the floating mechanism have an important influence on the impact energy, frequency, and power of the hydraulic rock drill. Based on orifice throttling theory, the static equilibrium position of a damping piston was calculated, and the characteristic parameters of the double damping system were summarized as damping flow $\left(Q_{\mathrm{d}}\right)$ and feed force $\left(F_{\mathrm{d}}\right)$. According to the characterization parameters of the double damping system, an experimental scheme of the floating characteristics of the double damping system was designed, and the combined experimental data of $Q_{\mathrm{d}}$ and $F_{\mathrm{d}}$ were obtained. The 40 groups of experimental data were extracted, and the relationship between the combination $\left(Q_{\mathrm{d}}, F_{\mathrm{d}}\right)$ and impact energy and frequency and power were analyzed. The combination $\left(Q_{\mathrm{d}}, F_{\mathrm{d}}\right)$ with maximum and minimum power was selected to analyze the motion law of an impact piston. The maximum drilling power was obtained at the combination $\left(Q_{\mathrm{d}}=8 \mathrm{~L} \cdot \mathrm{min}^{-1}, F_{\mathrm{d}}=16.25 \mathrm{kN}\right)$. The influence factors of the double damping system on impact performance were summarized, and the characteristics of the double damping system under optimal impact performance were obtained.

\section{Introduction}

Hydraulic rock drill is widely used in mining, coal mine excavation, railway, and highway tunnel and rock excavation projects with many advantages such as high efficiency, cleanliness, and safety. With the scale of mining and the large-scale tunneling, high frequency and high power have become an important development direction of hydraulic rock drills. At the same time, higher requirements have been put forward for energy absorption and vibration reduction technology. As a technological innovation of the single damping system, the double damping system emerged as the times require, and high-power hydraulic drills with the double damping system have been developed. It is an important trend to develop the high-power hydraulic rock drill with double damping system.

The double damping system uses single oil supply with constant flow and two damping chambers. It has the advantages of fast response, good energy absorption, and fast heat dissipation and is mostly used in high-power hydraulic rock drills. However, the double damping system also has its drawbacks, and its special floating characteristics bring inconvenience to debugging. The floating characteristic of the double damping system refers to that, in the process of working of rock drill, the moving elements such as damping piston are always in the floating state and move back and forth in the cylinder under the influence of external factors. Therefore, the double damping system is also called "floating damping system" [1-4]. Because of the importance of the damping system in the high-power rock drill, many experts and scholars have studied the interaction between damping system and impact system.

Oh et al. [5] established a unified model of rock, damping, and impact, based on Amesim software. The relationship between the pressure of the damping chamber and the motion law of the damping piston and the relationship between rock hardness and drilling efficiency are analyzed. Hu et al. [6] compiled a program interface to simulate the impact performance of rock drill and verified the simulation model by stress wave experiment. Yang et al. [7] built the numerical 
model of the hydraulic rock drill impact system by the bond graph method and optimized the key structural parameters. Seo et al. [8] established the whole model of hydraulic rock drill based on SimulationX software. The simulation model was validated by stress wave experiment. Then, the influence of the structure of the reversing valve and the damping system on the impact performance of rock drill was simulated and analyzed.

In the above research results, there are more studies on the impact system and damping system alone and fewer studies on the interaction between them. No scholars have studied the floating characteristics of the double damping system.

The internal motion elements such as shank and damping piston move as a whole under the action of the drilling reflection wave. Because the position of the shank determines whether the impact piston can impact the shank at the time of maximum impact energy, the impact performance of rock drill gets affected. In order to reduce the negative impact, it is necessary to research the floating characteristics, influencing factors, and changing rules of the double damping system.

\section{Working Principle of Impact and Double Damping Systems}

2.1. Working Principle of Hydraulic Rock Drill. The impact piston of hydraulic rock drill reciprocating moves under the action of hydraulic oil. When it reaches the limit position of the front end, it impacts the shank and generates the incident stress wave. The incident stress wave is transmitted to the rock through the shank, drill rod, and drill bit, and the rock is broken. Some of the stress waves without breaking rock are reflected back to the double damping system through the parts of the drill bit, drill rod, and shank, and the stress wave energy is absorbed by the double damping system, as shown in Figure 1.

2.2. Working Principle of Double Damping System. The double damping system of the hydraulic rock drill is mainly used to absorb the rebound energy of drill tail, so the damping system is also called the rebound energy absorption device of shank. Its structure is shown in Figure 2.

The impact force of the impact piston rebounds through rock and is transmitted to the damping piston through the drill bit, drill rod, shank, and spacer bush. The damping piston moves under the action of rebound force. The damping piston and the cylinder are separated by the 1st and 2nd damping chambers, and the 1st and 2nd damping chambers are connected by a one-way valve and an annular clearance and are connected with the damping accumulator through an internal pipeline.

The damping accumulator can absorb energy and rebound force. At the same time, it can push the drill tool to reset and finally tighten the bit to the rock bottom. The following points are the summarization of the two functions of the double damping system:
(1) The repeated transmission of reflected stress waves is prevented in drilling tools

(2) After the impact piston impacts the drill tool to break the rock, the double damping system makes the drill tool quickly tighten the rock before it impacts the drill tool again

\section{Characterization Parameters of Floating Characteristics}

The double damping system uses single oil supply with constant flow and two damping chambers. It has the advantages of quick response, good energy absorption effect, and fast heat dissipation. It is commonly used in heavy and high-power hydraulic rock drills. But the double damping system also has its drawbacks because of its special floating characteristics [9].

The floating characteristic of the double damping system refers to that the moving elements in the system are always in the floating state during the working process of rock drill and move around under the action of external factors. Therefore, the double damping system is also called "floating damping system."

As shown in Figure 2, the damping piston, spacer bush, and shank are the internal moving elements and move as a whole under the action of external forces. Because the position of the shank determines the position of the impact point, the impact performance of rock drill gets affected. In order to reduce the negative impact, it is necessary to study the floating characteristics, influencing factors, and changing rules of the double damping system [10].

When the hydraulic rock drill locates the borehole in the process of drilling, the damping system is affected by both feed force and rock reaction force. When the static equilibrium position is reached, the damping chambers' pressure is balanced with the rock reaction force [11].

In the working process of the double damping system of the hydraulic rock drill, the damping piston relies on the pressure of 1st and 2nd damping chambers and the control of the one-way valve connecting the damping chambers for reciprocating motion. The hydraulic oil pressure acting on the damping piston and the feed force are reciprocal forces, so formula (1) is established. The static equilibrium position of the damping piston is determined by the size of the opening formed by the leakage return hole, as shown in Figure 3:

$$
F_{0}=P_{\mathrm{d}} \cdot\left(A_{\mathrm{d} 1}+A_{\mathrm{d} 2}\right) \text {, }
$$

where $F_{0}$ is the feed force $(\mathrm{N}), P_{\mathrm{d}}$ is the damping chamber pressure $(\mathrm{MPa})$, and $A_{\mathrm{d} 1}$ and $A_{\mathrm{d} 2}$ are the working areas of 1 st and 2 nd damping chambers $\left(\mathrm{m}^{2}\right)$.

The pressure of the damping chamber is determined by the feed force on the premise that the structure of the double damping system is certain. Figure 3 is the oil circuit diagram of the double damping system; based on the principle of constant flow oil supply and orifice throttling theory, the differential pressure flow equation shown in formulas (2) 


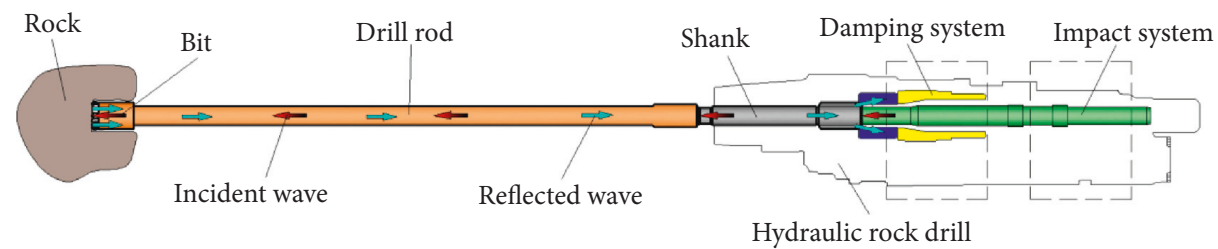

FIgURE 1: Working principle of hydraulic rock drill.

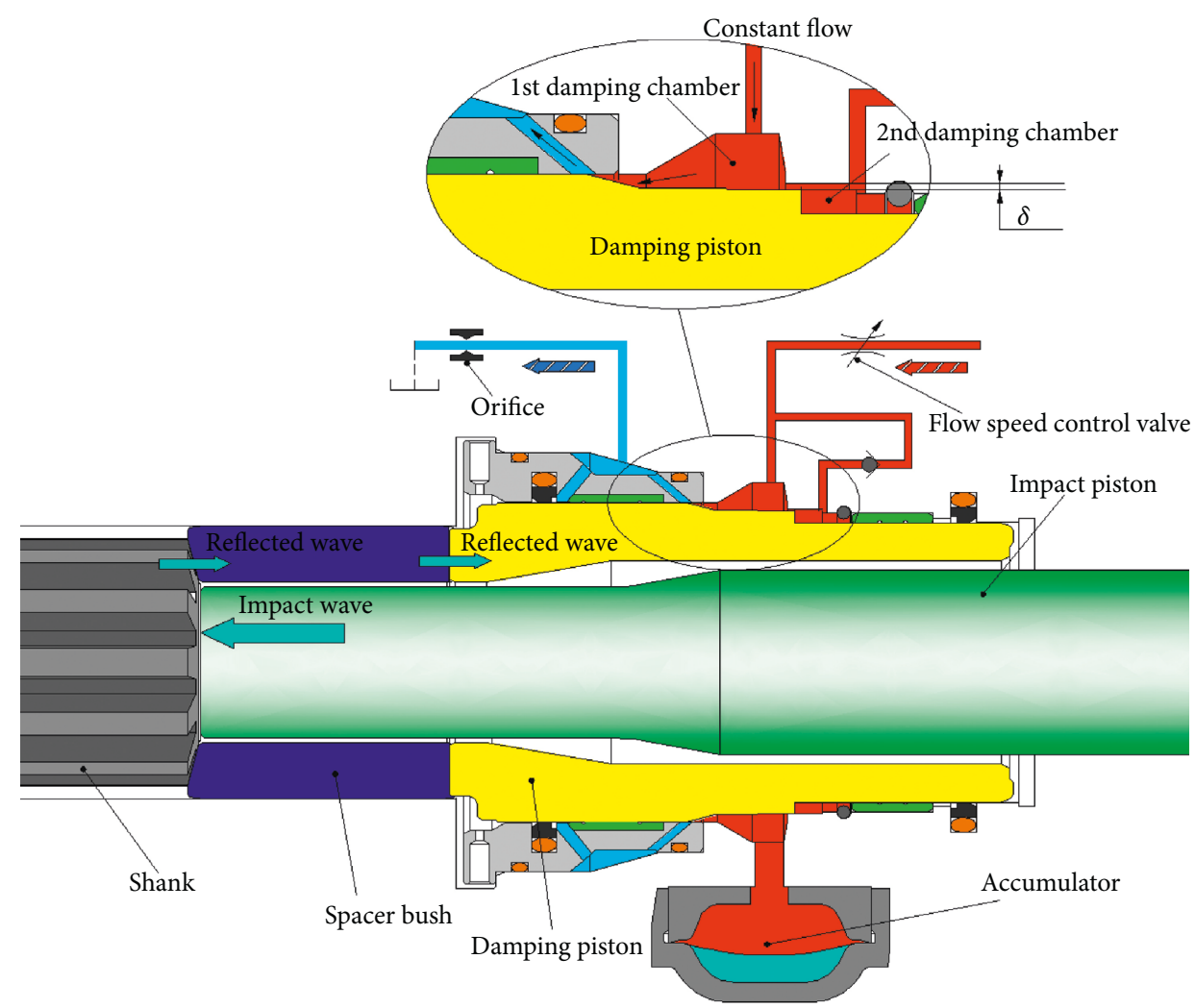

FIGURE 2: Working principle of the double damping system.

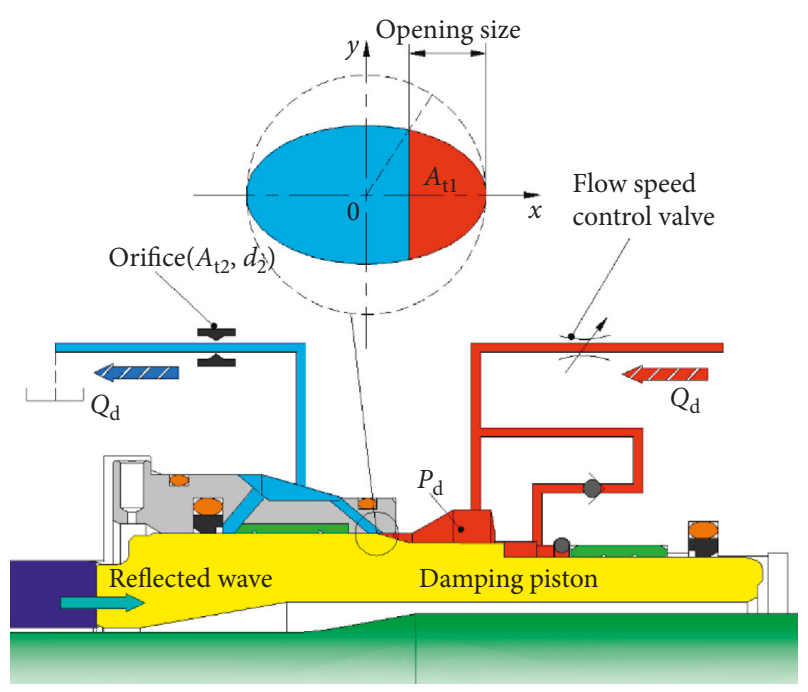

FIgURE 3: The oil circuit diagram of the double damping system. and (3) can be established to further determine the orifice flow area of the return orifice:

$$
\begin{aligned}
& Q_{\mathrm{d}}=C_{\mathrm{d}} \cdot A_{\mathrm{t} 2} \cdot \sqrt{\frac{2}{\rho} \cdot\left(P_{d 0}-P_{0}\right)}, \\
& \frac{Q_{\mathrm{d}}}{2}=C_{\mathrm{d}} \cdot A_{\mathrm{t} 1} \cdot \sqrt{\frac{2}{\rho} \cdot\left(P_{\mathrm{d}}-P_{\mathrm{d} 0}\right)}, \\
& A_{\mathrm{t} 2}=\frac{\pi}{4} \cdot d_{2}^{2},
\end{aligned}
$$

where $Q_{\mathrm{d}}$ is the damping flow $\left(\mathrm{L} \cdot \mathrm{min}^{-1}\right) ; C_{\mathrm{d}}$ is the flow coefficient, the value is $0.8 ; P_{\mathrm{d} 0}$ is the return chamber pressure $(\mathrm{MPa}) ; P_{0}$ is the return pressure of the damping system $(\mathrm{MPa}) ; \rho$ is the hydraulic oil density, the value is 850 $\left(\mathrm{kg} \cdot\left(\mathrm{m}^{3}\right) \cdot{ }^{-1}\right) ; A_{\mathrm{t} 1}$ is the orifice overflow area of the damping return chamber $\left(\mathrm{m}^{2}\right) ; A_{\mathrm{t} 2}$ is the orifice overflow area in the return pipeline $\left(\mathrm{m}^{2}\right)$; and $d_{2}$ is the orifice diameter $(\mathrm{m})$. 
The expressions of $A_{\mathrm{t} 1}$ can be obtained by using simultaneous formulas (1)-(4), as shown in the following formula:

$$
A_{\mathrm{t} 1}=\frac{Q_{\mathrm{d}}}{2 \cdot C_{\mathrm{d}} \cdot \sqrt{(2 / \rho) \cdot\left(\left(F_{0} /\left(A_{\mathrm{d} 1}+A_{\mathrm{d} 2}\right)\right)-P_{0}\right)-\left(4 Q_{\mathrm{d}} / C_{\mathrm{d}} \cdot \pi \cdot d_{2}^{2}\right)^{2}}} .
$$

The orifice overflow area of the damping return chamber is an ellipse as shown in formula (6), and the relationship between the position of the damping piston and the overflow area can be obtained, as shown in formula (7):

$$
\begin{aligned}
\frac{x^{2}}{a^{2}}+\frac{y^{2}}{b^{2}} & =1, \\
A_{\mathrm{t} 1} & =2 \cdot \int_{t}^{a} b \cdot \sqrt{1-\frac{x^{2}}{a^{2}}} \mathrm{~d} x .
\end{aligned}
$$

The analysis shows that the damping flow $\left(Q_{\mathrm{d}}\right)$ and the feed force $\left(F_{0}\right)$ are two key parameters for describing the floating characteristics of the double damping system. The impact performance of the hydraulic rock drill with floating characteristics of the double damping system can be analyzed and researched by changing the two parameters through the impact performance test of the rock drill.

\section{Testing Research on the Effect of Floating Characteristics on Impact Characteristics}

4.1. Testing System. The hydraulic rock drill impacts on the punching cylinder through the drill rod on the operating platform, and the punching cylinder simulates rocks with different hardness by changing the inlet pressure [12-14]. The pressure and flow curves of each passage of the damping system and impact system under different damping flow $\left(Q_{\mathrm{d}}\right)$ and the feed force $\left(F_{0}\right)$ are measured. The pressure data of the impact system are also obtained in the test system. The testing principle is shown in Figure 4 . The initial data settings are shown in Table 1.

\subsection{Adjustment of Characterization Parameters}

4.2.1. Damping Flow $\left(Q_{d}\right)$. As shown in Figure 5, the damping flow is measured by using the flow sensor on the flow measurement bench, and the signal is input to the secondary meter to display. The flow adjustment is realized by operating the flow speed control valve. The CT15V-B-B-6 turbine flow sensor of LERO company is selected, and the measuring range of the sensor is $1-15 \mathrm{~L} / \mathrm{min}$, the response time is $1 \mathrm{~ms}$, and the precision is $1 \% \mathrm{FS}$.

4.2.2. Feed Force $\left(F_{0}\right)$. As shown in Figure 6, the adjustment of feed force is realized by adjusting the internal pressure of the feed cylinder. The pressure sensor is installed in the rodless chamber of the feed cylinder. The signal is input to the secondary meter to display, and the adjustment of the feed pressure is realized by operating the proportional pressure regulating valve. The diameter of the rodless chamber of the propulsion cylinder is $63 \mathrm{~mm}$.

\subsection{Data Analysis}

4.3.1. Impact Performance of Rock Drill. The impact energy is obtained indirectly from the piston speed, which could not be measured directly. It can be converted to velocity through pressure analysis [15].

The pressure curve is integrated through the position of the impact point, and the velocity of the impact process is obtained using the following formula:

$$
F t=m v
$$

where $F$ is the action force of oil pressure on the impact piston in stroke process $(\mathrm{N})$; $t$ is the action time of the impact piston $(\mathrm{ms}) ; m$ is the mass of the impact piston $(\mathrm{kg})$; and $v$ is the velocity of the impact piston $\left(\mathrm{m} \cdot \mathrm{s}^{-1}\right)$.

The action force of oil pressure on the impact piston during rock drilling is shown in Figure 7. The impact piston is reciprocating in the cylinder, under the pressure of hydraulic oil in the front and rear chambers. The action force (F) can be expressed by using formula (9).

$$
F=P_{1} A_{1}-P_{2} A_{2}
$$

where $P_{1}$ is the front chamber pressure (MPa); $P_{2}$ is the rear chamber pressure $(\mathrm{MPa}) ; A_{1}$ is the effective working area of the rear chamber of the impact piston $\left(\mathrm{mm}^{2}\right)$; and $A_{2}$ is the effective working area of the back chamber of the impact piston $\left(\mathrm{mm}^{2}\right)$.

The action force $F$ acting on the impact piston is integrated:

$$
\int_{a i}^{b i} F \mathrm{~d} t=m v
$$

Formula (9) is substituted into formula (10):

$$
\int_{a i}^{b i}\left(P_{1} A_{1}-P_{2} A_{2}\right) \mathrm{d} t=m v \text {. }
$$

The speed of each moment is obtained using the following formula:

$$
v_{i}=\frac{A_{1} \int_{a i}^{b i} P_{1} \mathrm{~d} t-A_{2} \int_{a i}^{b i} P_{2} \mathrm{~d} t}{m} .
$$

The maximum impact energy is obtained when the velocity is maximum, so the impact energy can be obtained by using the following formula:

$$
E=\frac{1}{2} m v_{\max }^{2}
$$

The impact performance of the rock drill under multiple sets of the different combinations $\left(Q_{\mathrm{d}}, F_{\mathrm{d}}\right)$ are tested. The testing results are summarized, and the curves of impact energy and impact frequency are drawn, as shown in Figures 8 and 9.

It can be seen in Figure 8 that when the damping flow range is $8-9 \mathrm{~L} \cdot \mathrm{min}^{-1}$ and the feed force range is $15-20 \mathrm{kN}$, 


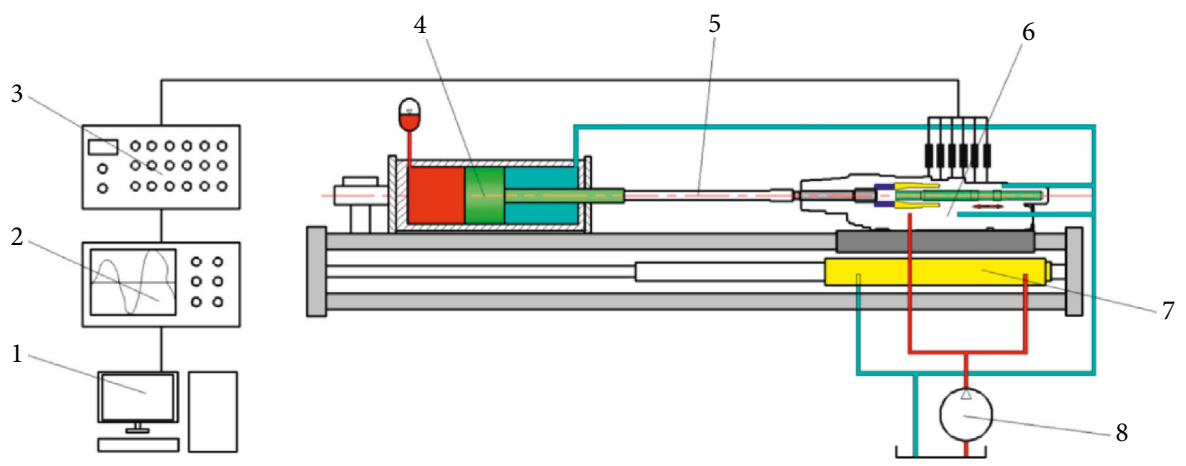

FIGURE 4: Impact and damping systems' test principle. (1) Computer; (2) data acquisition system; (3) signal amplifier; (4) punching cylinder; (5) drill rod; (6) hydraulic rock drill; (7) feed cylinder; (8) hydraulic pumping station.

TABLE 1: Initial data setting for experiments.

\begin{tabular}{lcc}
\hline Initial parameters & Value & Unit \\
\hline Impact overflow pressure & 23 & $\mathrm{MPa}$ \\
Impacting flow & 100 & $\mathrm{~L} \cdot \mathrm{min}^{-1}$ \\
Damping flow & $6 \sim 10$ & $\mathrm{~L} \cdot \mathrm{min}^{-1}$ \\
Feed force & $5 \sim 20$ & $\mathrm{kN}$ \\
\hline
\end{tabular}

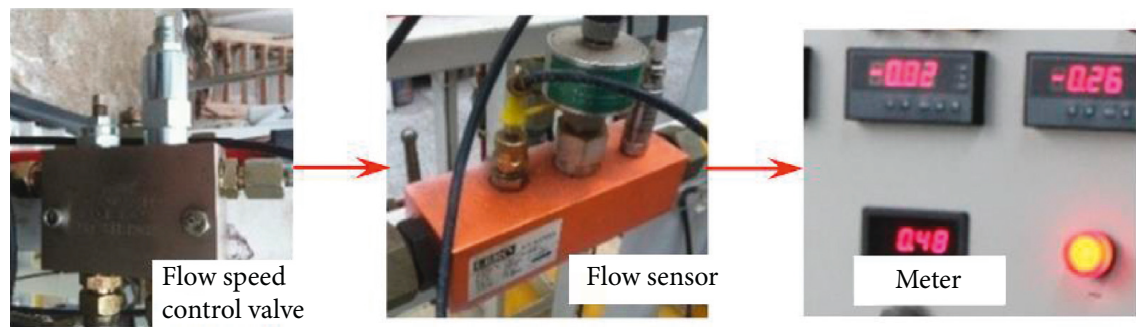

FIgURE 5: The adjustment and testing of the damping flow.

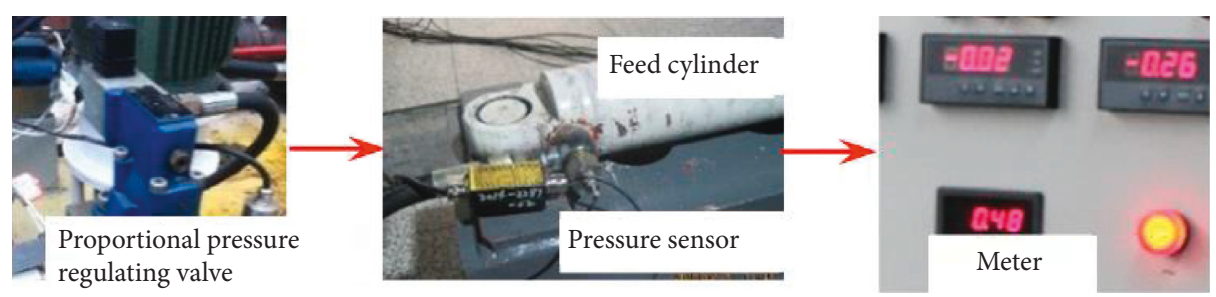

Figure 6: The adjustment and testing of the feed force.
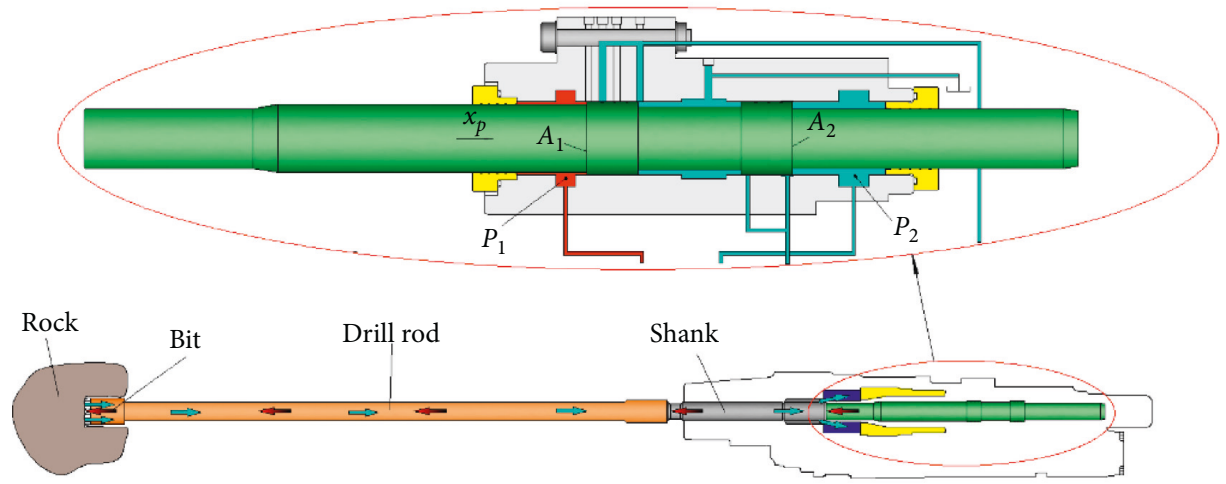

FIgURE 7: The action force of oil pressure on the impact piston during rock drilling. 


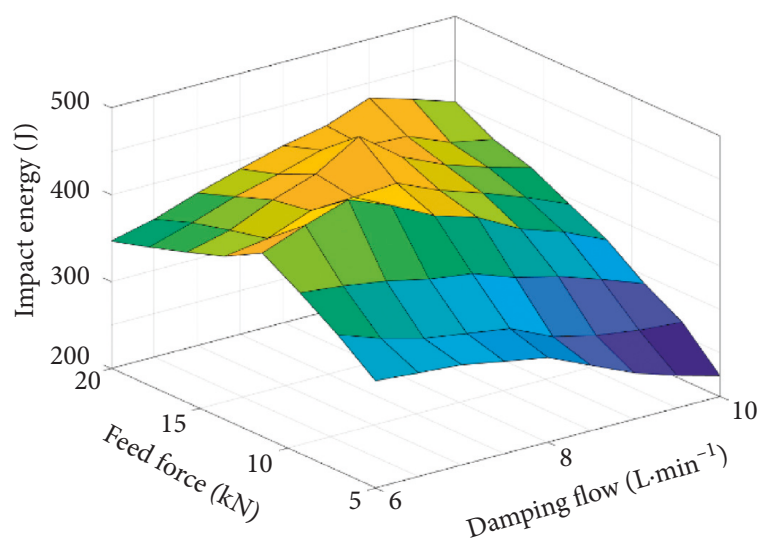

FIGURE 8: The comparisons of impact energy under different combinations $\left(Q_{\mathrm{d}}, F_{\mathrm{d}}\right)$.

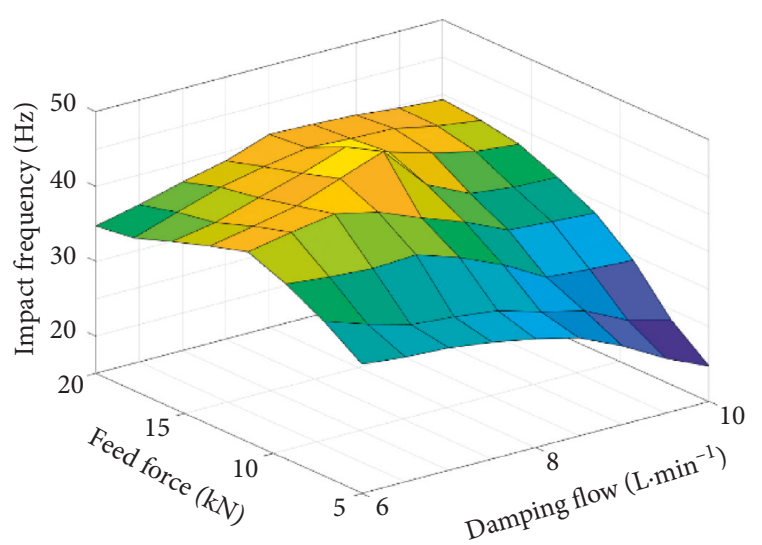

FIGURE 9: The comparisons of impact frequency under different combinations $\left(Q_{\mathrm{d}}, F_{\mathrm{d}}\right)$.

the impact energy can reach more than $400 \mathrm{~J}$, and the maximum value is $453.7 \mathrm{~J}$. When the damping flow range is $9-10 \mathrm{~L} \cdot \mathrm{min}^{-1}$ and the feed force range is $5-6 \mathrm{kN}$, the impact energy distribution is below $250 \mathrm{~J}$, and the minimum value is 223.7 J.

It can be seen in Figure 9 that when the damping flow range is $8-8.5 \mathrm{~L} \cdot \mathrm{min}^{-1}$ and the feed force range is $13.7-$ $16 \mathrm{kN}$, the impact frequency can reach more than $40 \mathrm{~Hz}$, and the maximum value is $45.4 \mathrm{~Hz}$. When the damping flow range is $9-10 \mathrm{~L} \cdot \mathrm{min}^{-1}$ and the feed force range is $5-6 \mathrm{kN}$, the impact frequency distribution is below $30 \mathrm{~Hz}$, and the minimum value is $19.7 \mathrm{~Hz}$.

According to formula (14), the drilling power distribution of the rock drill is obtained by combining the data of Figures 8 and 9, as shown in Figure 10:

$$
P=\frac{E \cdot f}{1000}
$$

where $P$ is the drilling power $(\mathrm{kW}), E$ is the impact energy $(J)$, and $f$ is the impact frequency $(\mathrm{Hz})$.

It can be seen in Figure 10 that the combination $\left(Q_{\mathrm{d}}, F_{\mathrm{d}}\right)$ of higher power of hydraulic rock drill distributes evenly along the polyline $\mathrm{AB}$ and $\mathrm{BC}$, with point $\mathrm{B}$ being the highest peak point. The drilling power drops rapidly on both sides of

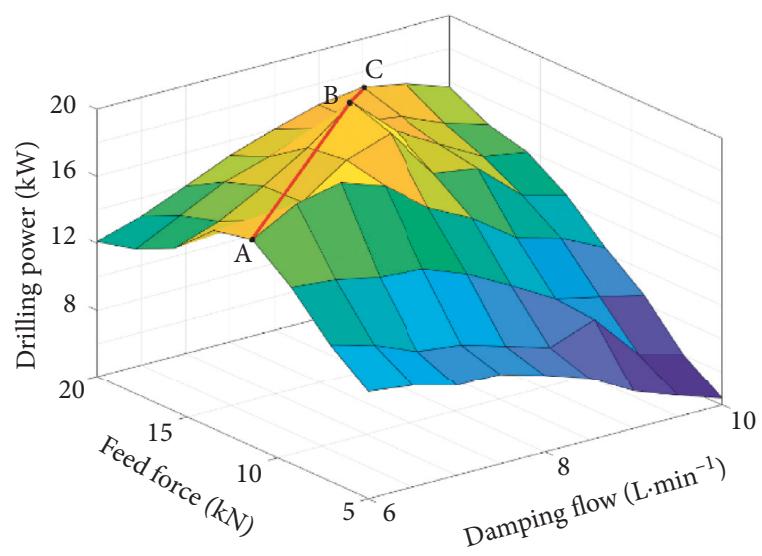

Figure 10: The comparisons of drilling power under different combinations $\left(Q_{\mathrm{d}}, F_{\mathrm{d}}\right)$.

the polyline. The following linear equation formulas of $\mathrm{AB}$ and $\mathrm{BC}$ are obtained according to the coordinates:

$$
\left\{\begin{array}{l}
\frac{Q_{\mathrm{d}}-6}{2}=\frac{F_{\mathrm{d}}-11.4}{4.85}=\frac{P-14.1}{5.6}(\mathrm{AB}), \\
\mathrm{Q}_{\mathrm{d}}-8=\frac{F_{\mathrm{d}}-16.25}{3.75}=\frac{P-19.7}{-2.5}(\mathrm{BC}) .
\end{array}\right.
$$

According to the distribution law of the drilling power near the polyline, when the damping flow range is $7.8-8.5 \mathrm{~L} \cdot \mathrm{min}^{-1}$ and the feed force range is $13.7-15 \mathrm{kN}$, the drilling power can reach more than $17 \mathrm{~kW}$, and the maximum value is $19.7 \mathrm{~kW}$. When the damping flow range is $9-10 \mathrm{~L} \cdot \mathrm{min}^{-1}$ and the feed force range is $5-6 \mathrm{kN}$, the drilling power distribution is below $6 \mathrm{~kW}$, and the minimum value is $4.6 \mathrm{~kW}$

The comparative analysis of the testing results shows that the impact performance of the rock drill is greatly affected by damping flow $\left(Q_{\mathrm{d}}\right)$ and feed force $\left(F_{\mathrm{d}}\right)$, but the internal mechanism of affecting the impact performance is not clear enough. Therefore, the following study is conducted from the movement law of the impact piston inside the rock drill.

4.3.2. Motion Law of Impact Piston. In the range of maximum drilling power and minimum drilling power, two groups of most representative data are selected, the combination $\left(8 \mathrm{~L} \cdot \mathrm{min}^{-1}, 16.25 \mathrm{kN}\right)$ corresponding parameters of maximum impact power, and the combination $\left(10 \mathrm{~L} \cdot \mathrm{min}^{-1}\right.$, $5 \mathrm{kN}$ ) corresponding parameters of minimum impact power. The effects of these two different conditions on the motion law of the impact piston are researched.

The test pressure curves of the impact piston under the different combinations $\left(Q_{\mathrm{d}}, F_{\mathrm{d}}\right)$ are shown in Figure 11. In order to better analyze the piston motion, the pressure curve is processed as shown in Figure 11 to obtain the motion law of the impact piston.

According to the analysis results in 4.3.1 and the derivation of formulas (8)-(12), the pressure curve is integrated and the velocity curve of the impact piston is obtained, as shown in Figure 12. 


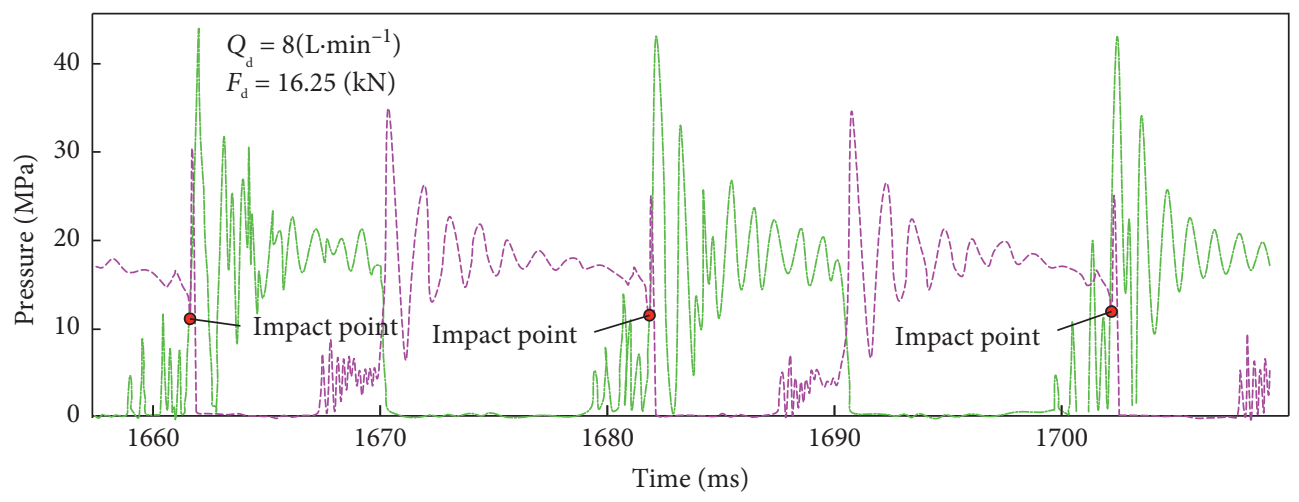

-.. . Front chamber

- - - Rear chamber

(a)

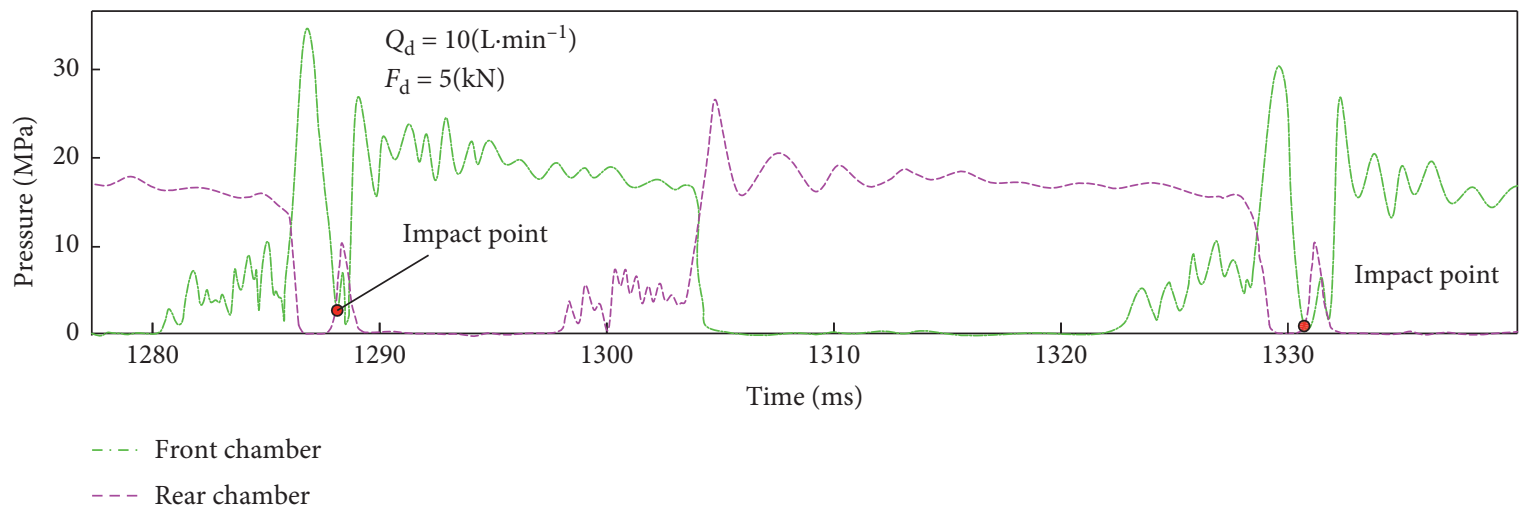

(b)

FigurE 11: The pressure curves of front and rear chambers of the impact piston under different combinations $\left(Q_{\mathrm{d}}, F_{\mathrm{d}}\right)$.

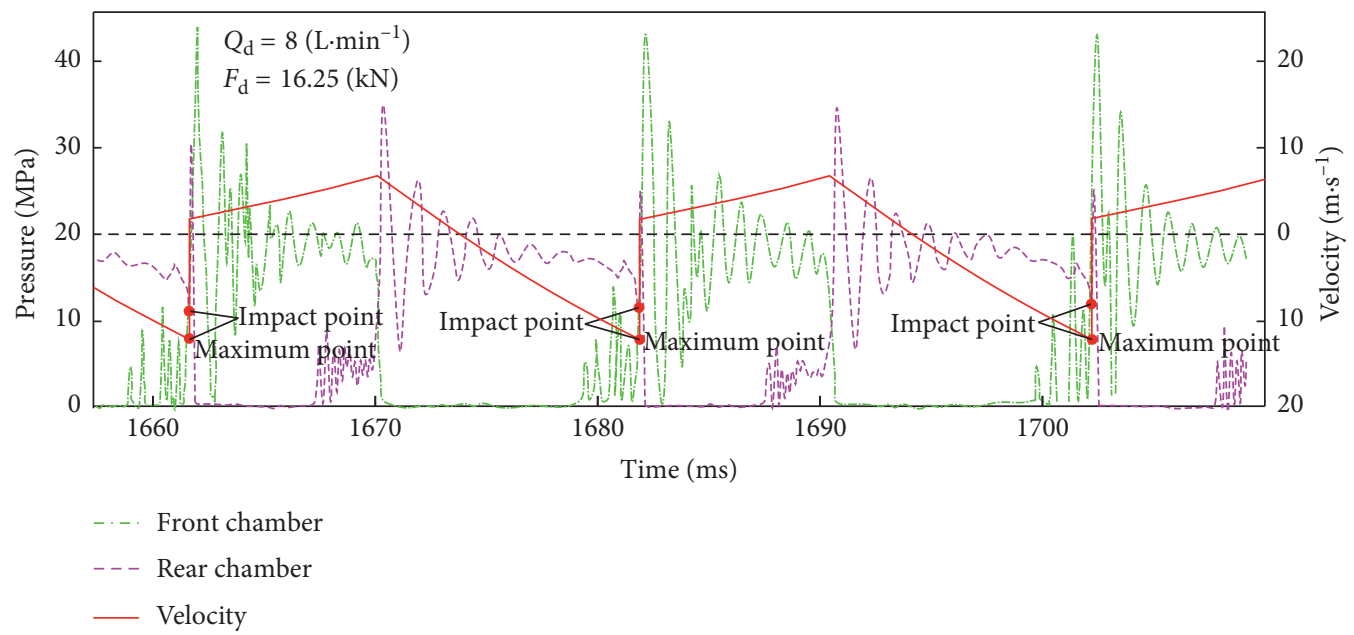

(a)

Figure 12: Continued. 


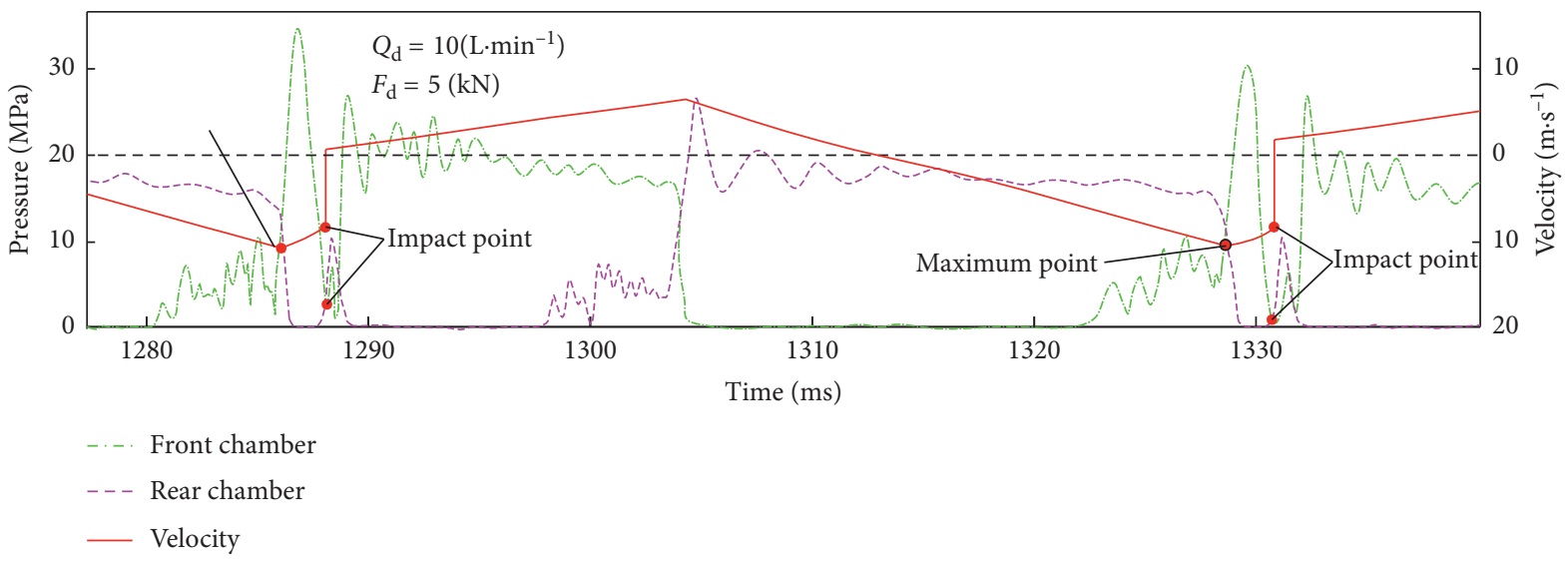

(b)

FIGURE 12: The comparisons of motion laws of the impact piston under different combinations $\left(Q_{\mathrm{d}}, F_{\mathrm{d}}\right)$.

It can be seen in Figure 12 that because of the rebound phenomenon when the impact piston impacts the shank, the rear chamber pressure will peak at this time, so it is easy to judge the time of the impact point.

Under the combination $\left(8 \mathrm{~L} \cdot \mathrm{min}^{-1}, 16 \mathrm{kN}\right)$, the impact piston has high frequency and high velocity, and the maximum value can reach $12.29 \mathrm{~m} \cdot \mathrm{s}^{-1}$. At this time, all the kinetic energy of the impact piston is used to break the rock.

Under the combination $\left(10 \mathrm{~L} \cdot \mathrm{min}^{-1}, 5 \mathrm{kN}\right)$, the impact piston has low frequency and slow velocity; although the maximum value can reach $10 \mathrm{~m} \cdot \mathrm{s}^{-1}$, the impact time delays. When the impact piston impacts the shank, the velocity has begun to drop to $8.5 \mathrm{~m} \cdot \mathrm{s}^{-1}$. At this time, only part of the kinetic energy of the impact piston can be used to break the rock.

\section{Conclusions}

The floating characteristics of internal components of the double damping system are analyzed, which can better solve the problem of energy absorption during rock drilling, but also has negative effects on the utilization of impact energy. The negative effects become obvious with the increase power of rock drill.

The static equilibrium position of the damping piston in the double damping system is discussed under the feed force, and the static equilibrium position model of the damping piston in the double damping system is established. Through the theoretical analysis of the model, two characteristic parameters of the floating characteristics of the double damping system, namely, the damping flow $Q_{\mathrm{d}}$ and the feed force $F_{\mathrm{d}}$, are obtained.

The effects of different the combination $\left(Q_{\mathrm{d}}, F_{\mathrm{d}}\right)$ on impact performance, including impact energy and frequency, are researched. These influences determine the output power of the hydraulic rock drill. In order to avoid the phenomenon that impact energy decreases and impact frequency decreases in engineering application, through experiments, 72 groups of the combination $\left(Q_{\mathrm{d}}, F_{\mathrm{d}}\right)$ were tested and analyzed, and the optimal combination was found.

The results show that damping flow and feed force have great influence on impact performance of the rock drill. The maximum drilling power is obtained at the combination
$\left(Q_{\mathrm{d}}=8 \mathrm{~L} \cdot \mathrm{min}^{-1}, F_{\mathrm{d}}=16.25 \mathrm{kN}\right)$, while the other parameters only obtain lower drilling power. The reason is that the position of the impact piston impacting the shank is uncertain because of the floating characteristic of the double damping system. Only when the impact piston impacts the shank at the maximum speed, the drilling power will be increased. The difference between the maximum and the minimum drilling power due to position uncertainty is $15.1 \mathrm{~kW}$.

\section{Data Availability}

All the data from tests and curves used to support the findings of this study are included within the article. The experimental method in the paper "Fault Diagnosis Research on Impact System of Hydraulic Rock Drill Based on Internal Mechanism Testing Method" is used to support this study, and these prior studies (and datasets) are cited at relevant places within the text as references [16].

\section{Conflicts of Interest}

The authors declare that they have no conflicts of interest.

\section{Acknowledgments}

This research was supported by the Education Department Excellent Youth Item of Hunan Province (Grant no. 18B397), Natural Science Foundation of Hunan Province (Grant no. 2019JJ50404), Provincial Specialty Disciplines of Higher Education Institutions in Hunan Province (Grant no. XJT [2018] 469), and General Project of Changde Science and Technology Bureau (Grant nos. 2018J051 and CCQZ[2018]6).

\section{References}

[1] S. Liu, H. Li, and H. Chang, "Drilling performance of rock drill by high-pressure water jet under different configuration modes," Shock and Vibration, vol. 2017, no. 10, Article ID 5413823, 14 pages, 2017.

[2] B.-J. Ryu, H.-H. Han, G.-S. Lee, K.-Y. Ahn, and C.-R. Lee, "Dynamic response analysis of a cantilevered beam due to an 
elastic impact," International Journal of Precision Engineering and Manufacturing, vol. 11, no. 4, pp. 539-547, 2010.

[3] H. Li, Y. Shen, Q. Wang, Y. Wang, D. Bai, and Z. Deng, “A piezoelectric-driven rock-drilling device for extraterrestrial subsurface exploration," Shock and Vibration, vol. 2018, Article ID 8368012, 12 pages, 2018.

[4] S. Min-Fei, Q.-H. He, Z. Hong-Qiang et al., "Study on simulation of impact performance and working pressure of hydraulic drifter," Journal of Wuhan University of Technology, vol. 33, no. 8, pp. 133-137, 2011.

[5] J.-Y. Oh, G.-H. Lee, H.-S. Kang, and C.-S. Song, "Modeling and performance analysis of rock drill drifters for rock stiffness," International Journal of Precision Engineering and Manufacturing, vol. 13, no. 12, pp. 2187-2193, 2012.

[6] Q. Hu, C. Yang, H. Zheng, and M. Chen, "Dynamic simulation and test research of impact performance of hydraulic rock drill with no constant-pressurized chamber," Automation in Construction, vol. 37, no. 1, pp. 211-216, 2014.

[7] S.-Y. Yang, Y.-B. Ou, Y. Guo, and X.-M. Wu, "Analysis and optimization of the working parameters of the impact mechanism of hydraulic rock drill based on a numerical simulation," International Journal of Precision Engineering and Manufacturing, vol. 18, no. 7, pp. 971-977, 2017.

[8] J. Seo, D.-K. Noh, G.-H. Lee, and J.-S. Jang, "A percussion performance analysis for rock-drill drifter through simulation modeling and experimental validation," International Journal of Precision Engineering and Manufacturing, vol. 17, no. 2, pp. 163-170, 2016.

[9] Y. Guo, S. Y. Yang, D. S. Liu, L. Y. Zhang, and J. W. Chen, "Impact performance for high frequency hydraulic rock drill drifter with sleeve valve," International Journal of Fluid Machinery and Systems, vol. 9, no. 1, pp. 39-46, 2016.

[10] J.-P. Hu and Q. Hu, "Oil pressure pulse features of a hydraulic impactor with an overlapped oil distributing valve," Journal of Vibration and Shock, vol. 33, no. 24, pp. 158-163, 2014.

[11] G.-P. Yang, R.-L. Wang, B. Chen, and J.-H. Gao, "Modeling and simulation of hydraulic breaker system," China Journal of High Way and Transport, vol. 24, no. 3, pp. 121-126, 2011.

[12] S. Kahraman, N. Bilgin, and C. Feridunoglu, "Dominant rock properties affecting the penetration rate of percussive drills," International Journal of Rock Mechanics and Mining Sciences, vol. 40, no. 5, pp. 711-723, 2003.

[13] L. E. Chiang and D. A. Elías, "Modeling impact in down-thehole rock drilling," International Journal of Rock Mechanics and Mining Sciences, vol. 37, no. 4, pp. 599-613, 2000.

[14] G. L. Cavanough, M. Kochanek, J. B. Cunningham, and I. D. Gipps, "A self-optimizing control system for hard rock percussive drilling," IEEE/ASME Transactions on Mechatronics, vol. 13, no. 2, pp. 153-157, 2008.

[15] B. Lundberg and M. Okrouhlik, "Influence of 3D effects on the efficiency of percussive rock drilling," International Journal of Impact Engineering, vol. 25, no. 4, pp. 345-360, 2011.

[16] Y. Li, Y. Luo, and X. Wu, "Fault diagnosis research on impact system of hydraulic rock drill based on internal mechanism testing method," Shock and Vibration, vol. 2018, Article ID 4928438, 9 pages, 2018. 


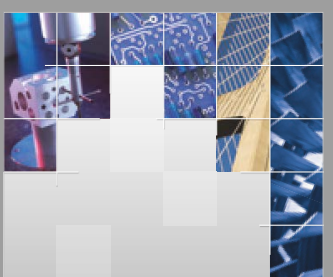

\section{Enfincering}
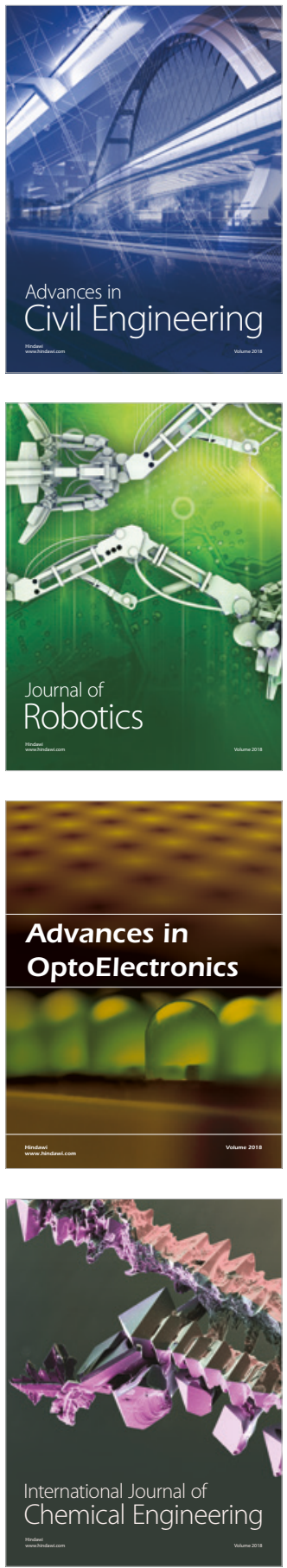

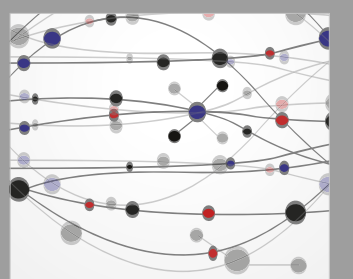

\section{Rotating \\ Machinery}

The Scientific World Journal

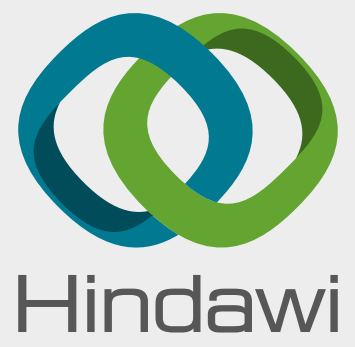

Submit your manuscripts at

www.hindawi.com
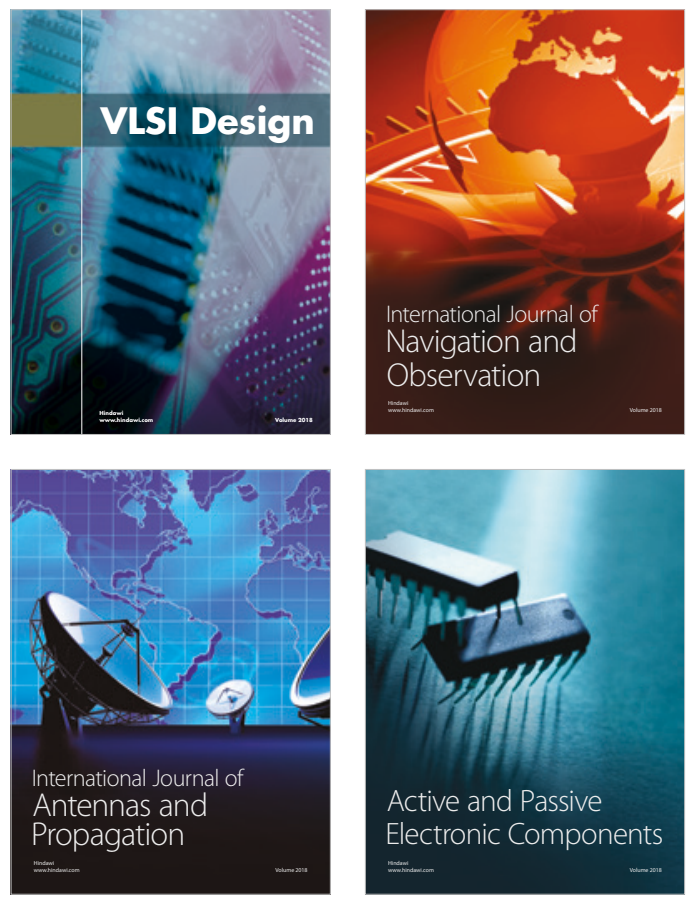
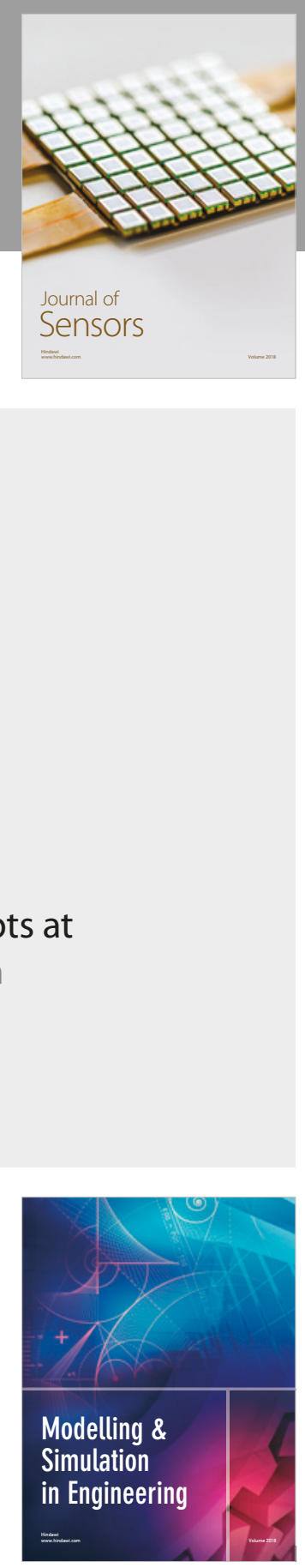

\section{Advances \\ Multimedia}
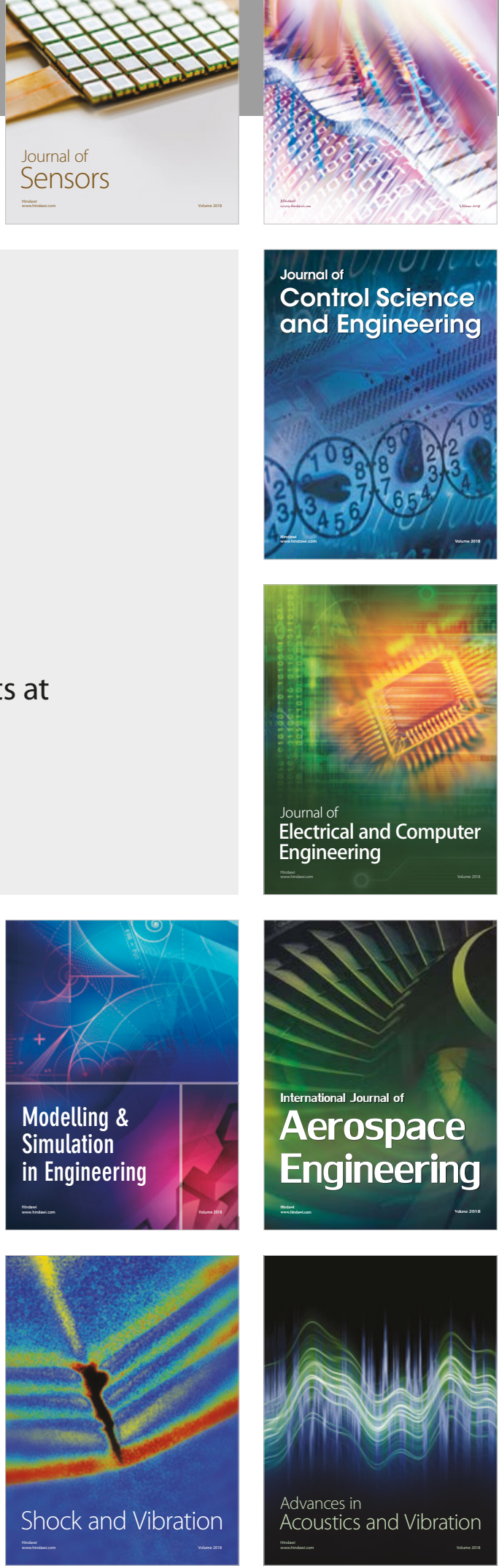